\section{New Insights into Sponge Spicules Biosilicification by Solid-State NMR and Dynamic Nuclear Polarization}

\section{SYLVIE MASSE ${ }^{1}$, GUILLAUME P. LAURENT ${ }^{2}$ AND ANDRZEJ PISERA ${ }^{3}$}

${ }^{1} \mathrm{CNRS}$ - Sorbonne Université

${ }^{2}$ Sorbonne Université - CNRS

${ }^{3}$ Polish Academy of Sciences

Presenting Author: sylvie.masse@upmc.fr

This work gives new insights into the characterization of siliceous sponge spicules with the help of solid-state Nuclear Magnetic Resonance (NMR) and Dynamic Nuclear Polarization (DNP). Sponges, one of the most primitive animals are exclusively aquatic sessile organisms. In the case of marine siliceous sponges, an internal skeleton composed of spicules serves as to stiffen the soft sponge body, helping the species for protection and anchoring. The siliceous spicules, formed during a biomineralization process, are not purely mineral structures but rather biocomposites of silica and organics[1] from whom the interfaces study is promising.

Solid-state NMR is one of the most versatile tools of characterization in materials science. It offers a large panel of experiments which allow the in-depth and non-destructive characterization of materials at the atomic level (including amorphous compounds). For instance, two-dimensional (2D) experiments provide interesting heteronuclear correlations depicting the organic-inorganic interface. However, this technique suffers from low sensitivity and long acquisition times.

The peculiar case of natural samples such as sponge spicules is particularly tricky, because they contain only small amounts of carbon (e.g., 2-7 wt\% $\mathrm{C}$ in the already-studied specimen), for which only a part are active isotopes (natural abundance of ${ }^{13} \mathrm{C}$ is $\sim 1.1$ at $\%$ ). Because no isotopic enrichment is possible in our case, only methodological and instrumental developments could help to get the signal faster.

Solid-state DNP NMR offers new opportunities in the field of hybrid materials and their interfaces investigation. In practice, DNP is known to drastically enhance the NMR signal sensitivity (up to x100 in sensitivity, that means x10.000 in experimental time), rending possible the recording of $2 \mathrm{D}$ experiments in natural abundance in remarkably limited experimental time[2].

[1] S. Masse, A. Pisera, G. Laurent, and T. Coradin, 'A Solid State NMR Investigation of Recent Marine Siliceous Sponge Spicules', Minerals, 6/1 (2016), 21.

[2] Y. Geiger, H. E. Gottlieb, Ü. Akbey, H. Oschkinat, and G. Goobes, 'Studying the Conformation of a Silaffin-Derived Pentalysine Peptide Embedded in Bioinspired Silica using Solution and Dynamic Nuclear Polarization Magic-Angle Spinning NMR', Journal of the American Chemical Society, 138/17 (2016), 5561-67.

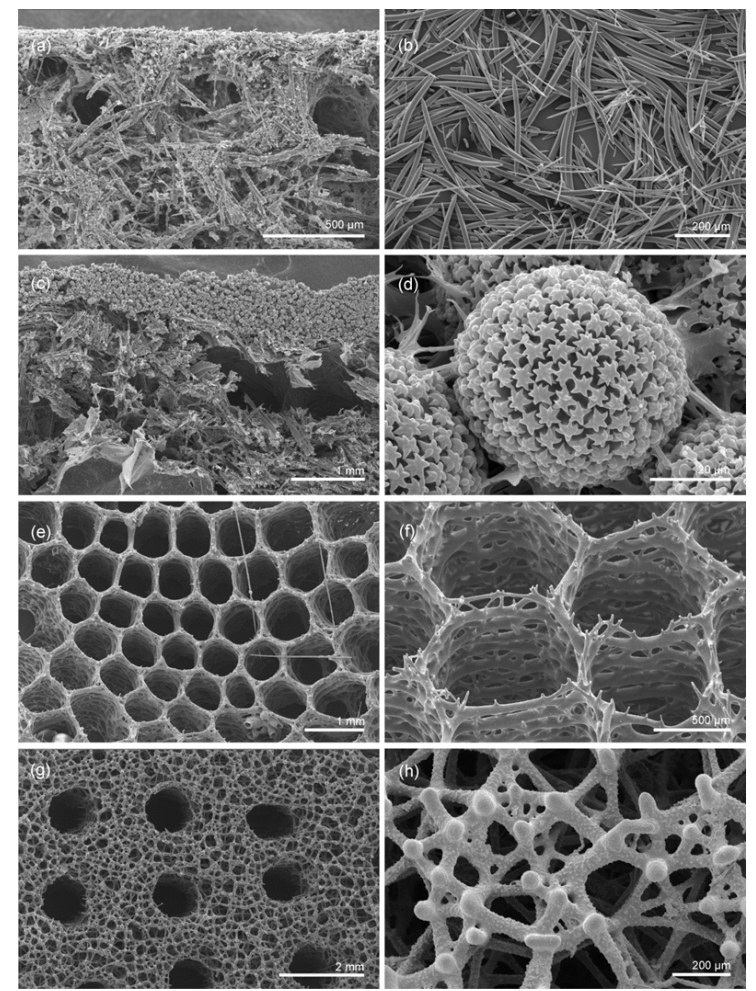

Figure 1. SEM images of the four investigated samples. (a,b) Petrosid sp. demosponge PETRO: (a) untreated, scale bar $=500 \mu \mathrm{m}$, (b) after organics removal, scale bar $=200 \mu \mathrm{m}$; (c,d) Geodia sp. demosponge GEODIA: (c) untreated, scale bar $=1 \mathrm{~mm}$, (d) untreated, scale bar $=20 \mu \mathrm{m}$; $(\mathbf{e}, \mathbf{f})$ Aphrocallistes sp. hexactinellid sponge APHRO: (e) untreated, scale bar $=1$ $\mathrm{mm}$, (f) after organics removal, scale bar $=500 \mu \mathrm{m} ;(\mathrm{g}, \mathrm{h})$ Laocoetis perion $\mathrm{sp}$. hexactinellid LAOCO: $(\mathrm{g})$ after organics removal, scale bar $=2 \mathrm{~mm}$, $(\mathrm{h})$ after organics removal, scale bar $=200 \mu \mathrm{m}$.

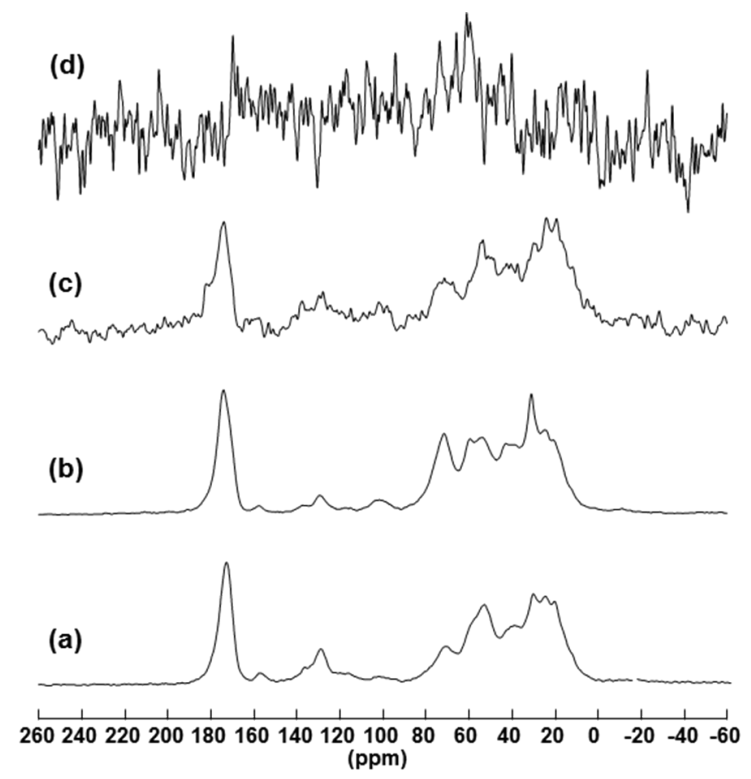

Figure 2. ${ }^{13} \mathrm{C} C P$ MAS solid-state NMR spectra of the four investigated samples: (a) Figure 2.
PETRO (number of scans $=79,200$ ), (b) GEODIA (number of scans $=113,203$ ), (c) APHRO (number of scans $=98,320$ ) and (d) LAOCO (number of scans $=171,580$ ). For all spectra, the ${ }^{1} \mathrm{H}-{ }^{13} \mathrm{C}$ contact time was $1 \mathrm{~ms}$ and the recycle delay was $2 \mathrm{~s}$. 